\title{
Risk factors associated with bacteremia in burn children admitted to a specialized pediatric intensive care unit: A case-control study
}

\author{
Hugo Basilico, M.D. ${ }^{a}$, Sebastián García, M.D. ${ }^{a}$ and Lucas Pintos, M.D. ${ }^{a}$
}

\begin{abstract}
Introduction. Infections due to bacteremia in burn patients are a common cause of complications and an extended length of stay. Knowing causative microorganisms and identifying associated risk factors allow to reduce infectious complications, morbidity, mortality, and health care expenditure. This study assesses the extent of the association between risk factors and bacteremia in burn patients and identifies the most common microorganisms found in blood cultures.

Population and methods. Case-control study conducted at the Burn Intensive Care Unit of Hospital dePediatríaS.A.M.I.C. “Prof. Dr.Juan P. Garrahan" between June ${ }^{\text {st }}, 2014$ and September $30^{\text {th }}, 2019$ in patients with bacteremia events and a positive blood culture (cases) and patients with a negative blood culture (controls).

Results. During the study period, 29 cases of bacteremia were identified. The median length of stay at the time of bacteremia was 23 days. The most commonly identified microorganism was Pseudomonas (7 cases). The only risk factor that showed a significant association was the presence of a central venous line for 7 days or more (OR: 3.18 ; $95 \%$ confidence interval: 1.20 8.38). The overall mortality rate was $9.1 \% ; 13.8 \%$ for cases and $3.4 \%$ for controls.

Conclusions. Central venous lines for more than 7 days are an independent risk factor for bacteremia in critically ill burn children. No statistically significant association was established with other studied risk factors. Pseudomonas, Acinetobacter, and coagulase-negative Staphylococcus were the most common microorganisms found in bacteremia.

Key words: bacteremia, burn injuries, infections, morbidity, mortality.
\end{abstract}

http: / / dx.doi.org/10.5546/aap.2021.eng.325

To cite: Basílico H, García S, Pintos L. Risk factors associated with bacteremia in burn children admitted to a specialized pediatric intensive care unit: A casecontrol study. Arch Argent Pediatr 2021;119(5):325-330.

\section{INTRODUCTION}

Approximately $75 \%$ of pediatric patients with burns are younger than 5 years; the main place where burns occur is their home. The most common etiology are hot liquids among children younger than 4 years and direct fire among older children. ${ }^{1}$

Infections are a cause of complications and a longer length of stay. ${ }^{2}$ In addition, they are still a significant cause of morbidity and mortality and, although mortality has decreased as a consequence of advances in clinical and surgical management and complication prevention, mortality secondary to infection from a burn injury is still very high ${ }^{3}$ and is the main cause of mortality among burn patients. ${ }^{4}$

Infections are common due to the damage in the skin barrier, the destruction of the local flora, and the alteration of immunity resulting in favorable conditions for bacterial colonization and the development of treatment-resistant microorganisms. ${ }^{5}$ Patients become colonized by endogenous microorganisms from the skin, the gastrointestinal tract or the airways. Among hospitalized patients, colonization may occur in the hospital setting and involve multidrug-resistant microorganisms. Staphylococcus aureus, Pseudomonas aeruginosa, and Enterobacteriaceae are the most frequent ones. ${ }^{6-8}$ Bacteremia is usually the result of the invasion of microorganisms in the skin, although it may also develop at the time of a surgical debridement or due to central venous line colonization, urinary tract infection or bacterial translocation from the respiratory tract. ${ }^{9}$ The American Burn Association (ABA) criteria for the diagnosis of sepsis 
( 3 or more of the following criteria: temperature $>39^{\circ} \mathrm{C}$ or $<36.5^{\circ} \mathrm{C}$, progressive tachycardia, progressive tachypnea, thrombocytopenia, hyperglycemia, and feeding intolerance) have a limited correlation with the presence of bacteremia confirmed by blood culture, with a $78.2 \%$ sensitivity and a $49.5 \%$ specificity. ${ }^{10,11}$

The objective of this study was to assesses the extent of the association between risk factors and bacteremia in burn patients, and identify the most common microorganisms found in blood cultures and their respective antibiotic sensitivity.

\section{POPULATION, MATERIALS, AND METHODS}

Study conducted at the Burn Intensive Care Unit of Hospital de Pediatría S.A.M.I.C. "Prof. Dr. Juan P. Garrahan" in the Autonomous City of Buenos Aires between June 1 ${ }^{\text {st }}, 2014$ and September 30 ${ }^{\text {th }}, 2019$.

Design: Prevalent case-control study. Data were collected retrospectively from electronical medical records.

\section{Inclusion criteria}

- Cases: Patients aged 0-17 years and 11 months who, during hospitalization, developed bacteremia (positive blood culture) in the study period.

- Controls: Patients aged 0-17 years and 11 months admitted to the pediatric intensive care unit (PICU) in the same period with a negative blood culture that had been obtained for suspected bacteremia. Data were collected from the electronic medical records of all patients who developed bacteremia as reported by the Department of Epidemiology and Infectious Diseases and controls were randomly selected among the patients with a negative blood culture in a 1:2 case-control ratio.

\section{Exclusion criteria}

Bacteremia event confirmed in a different facility; ignorance of number of days since venous line placement or about admission to the operating room in the previous 24 hours in patients referred from another facility.

\section{Description of outcome measures}

- Dependent outcome measure (bacteremia): presence of isolated microorganism in blood culture in the 5 days after collecting the sample.
- Independent outcome measures (exposure): age in months, body surface area burned (percentage of damaged skin), length of stay (days since admission to our hospital), urinary catheter (presence or absence), time since placement and site of central venous line ( 7 days or less and more than 7 days, and anatomic site of insertion), mechanical ventilation (MV) (days of MV), immediate surgery (admission to the operation room 24 hours prior to bacteremia development).

Statistical analysis: Data were collected from the electronic medical records of patients who developed bacteremia as reported by the Department of Epidemiology and Infectious Diseases and controls' medical records were randomly selected. Qualitative outcome measures were compared using a $\chi^{2}$ test, whereas quantitative ones with a normal distribution were compared using Student's $t$ test and those with an asymmetrical distribution, with Wilcoxon's test. Odds ratios (ORs) were estimated to assess the extent of the association with risk factors. Data were processed with the InfoStat ${ }^{\circledR}$, version 2020 (Universidad Nacional de Córdoba) and Epidat ${ }^{\circledR}$, version 4.1 (Pan American Health Organization) software programs.

Bias control: All cases of bacteremia reported in the epidemiological surveillance sheets were identified and controls were randomly selected in compliance with the inclusion and exclusion criteria mentioned above for both groups.

Ethical aspects: This study was conducted in compliance with the laws and regulations in force in relation to ethical review guidelines and was approved by the hospital's Research Committee. Data were collected using encrypted identifiers and protecting patient identity. Given the observational and retrospective nature of the study, informed consents were not required.

\section{RESULTS}

During the study period, 230 burn patients were hospitalized, $61 \%$ were males; the median age of the study population was 32 months, with a range between 2 months and 14 years. Table 1 describes the characteristics of cases and controls. A total of 29 bacteremia events were diagnosed in 16 patients $(6.96 \%) ; 58$ controls were selected.

Among patients younger than 12 months, 5 cases of bacteremia $(17.8 \%)$ and 6 controls $(10.2 \%)$ were identified, but no statistically significant association was established.

The percentage of total body surface area 
(TBSA) burned ranged between $15 \%$ and $87 \%$, with an average of $50 \%$ and a standard deviation (SD) of 20.7, with no statistical differences in terms of number of bacteremia events at the cutoff of $30 \%$ of TBSA burned.

The median length of stay at the time of bacteremia was 23 days, whereas the median use of mechanical ventilation (MV) was 21 days. None of these 2 outcome measures showed a statistically significant association.

The overall mortality rate among patients hospitalized in the study period was $9.1 \% ; 13.8 \%$ for cases and $3.4 \%$ for controls $(p=0.003)$.

A total of 27 bacteremia events were observed in patients who had a central venous line: 16 for $>7$ days and 11 for $\leq 7$ days after placement. The statistical analysis showed an association for a duration of central venous line higher than 7 days as a risk factor for bacteremia $(p=0.017$; $95 \%$ confidence interval [CI]: 3.18-8.38). The most common central venous line site was the femoral vein $(74 \%)$, followed by the jugular vein $(18.5 \%)$, and the subclavian vein $(7.5 \%)$; no association was established between the site of placement and a higher risk for infection (Table 2).

TABLE 1. Case and control characteristics

\begin{tabular}{lccc}
\hline Characteristics & $\begin{array}{c}\text { Cases } \\
(\mathbf{n}=\mathbf{2 9 )}\end{array}$ & $\begin{array}{c}\text { Controls } \\
(\mathbf{n}=\mathbf{5 8})\end{array}$ & $p$ value \\
\hline Age (months) & 32 & 113 & 0.01 \\
Burn (\%) & 50 & 35 & 0.15 \\
MV (days) & 21 & 14 & 0.11 \\
Length of stay (days) & 23 & 16 & 0.12 \\
Urinary catheter (\%) & 90 & 78 & 0.16 \\
Mortality (\%) & 13.8 & 3.4 & 0.003 \\
Admission to the & & & \\
operating room (\%) & 51 & 62 & 0.35 \\
\hline
\end{tabular}

MV: mechanical ventilation.
Surgical management was proposed as a risk factor and patients who developed bacteremia in the 24 hours after admission were identified; no statistically significant association was established, as was the case with urinary catheter placement (Table 3).

The microorganisms most commonly isolated included $P$. aeruginosa (7 cases), Acinetobacter spp. (5 cases), and coagulase-negative Staphylococcus ( 4 cases). Table 4 shows microbiological isolation by microorganism and site; $S$. aureus was identified only in 3 cases. In relation to resistance to the antibiotics used as initial empiric therapy for suspected sepsis or decompensation, meropenem resistance was considered in Gram-negative microorganisms and methicillin resistance, in Gram-positive ones; only 1 patient showed meropenem-resistant $P$. aeruginosa and there was a single case of methicillin-resistant S. aureus (MRSA).

\section{DISCUSSION}

A better knowledge of risk factors, etiology, and antibiotic sensitivity in bacteremia cases developed in critically ill burn patients allows to reduce morbidity and mortality. In the studied population, the burned body surface area ranged between $15 \%$ and $87 \%$, with an average of $50 \%$, turning the population into critically ill and susceptible to multiple risk factors for infection.

Considering the severity of bacteremia in burn children and the fact that microbiological isolation varies from one facility to another, it is necessary to know the local epidemiology of each institution. In our hospital, the most commonly isolated microorganisms ( $P$. aeruginosa, Acinetobacter, and $S$. aureus) account for approximately $50 \%$ of cases, which is consistent with reports published by different specialized centers. ${ }^{8,9,12-14}$ In a study conducted by Fochtmann-

TABLE 2. Characteristics of central venous lines

\begin{tabular}{lcccc}
\hline & Cases & Controls & $p$ value & OR (95\% CI) \\
\hline $\begin{array}{l}\text { Duration } \\
\quad 7 \text { days }\end{array}$ & 16 & & & $3.18(1.2-8.4)$ \\
$\quad \leq 7$ days & 11 & 1 & 0.017 & \\
Site & & 35 & & $2.10(0.4-10.9)$ \\
$\quad$ Femoral vein & 20 & & 0.36 & $2.85(0.4-19.6)$ \\
$\quad$ Jugular vein & 5 & 38 & 0.27 & $1.33(0.14-2.4)$ \\
$\quad$ Subclavian vein & 2 & 7 & 0.79 & \\
\hline
\end{tabular}

OR: odds ratio, CI: confidence interval. 
Frana et al., bloodstream infections were caused by Gram-negative bacteria (46\%), Grampositive bacteria $(40 \%)$, and fungi $(14 \%)$. The most commonly isolated microorganisms were Enterococcus, Candida, Pseudomonas, Enterobacter, S. aureus, coagulase-negative Staphylococcus, and Klebsiella. ${ }^{12}$ In 2017, in a referral facility of Colombia, Ramirez-Blanco et al. reported the most commonly found microorganisms: $P$. aeruginosa, A. baumannii, Escherichia coli, S. aureus, and Klebsiella pneumoniae; ${ }^{15}$ and the results observed were similar to those of our study. However, other studies identified Gram-positive bacteria as the most frequent cause of bacteremia in burn patients $(66.4 \%)$, followed by Gramnegative bacteria $(22.1 \%)$, and fungi $(11.5 \%)$, especially in the first week of admission. ${ }^{7}$
If a severe burn patient suffers a clinical decompensation, an infectious complication should be suspected and cultures should be performed to initiate or extend the antibiotic therapy..$^{16}$ An inadequate initial empiric therapy may increase mortality. ${ }^{17,18}$ In a study conducted by Devrim et al., 8 out of 9 bacteremia cases evidenced carbapenem-resistant $P$. aeruginosa; 1 isolation of $K$. pneumoniae $(12.5 \%)$; 2 cases of positive extended-spectrum beta-lactamase (ESBL)-producing E. coli (22.2\%), and 27 out of 70 cases of methicillin resistence. ${ }^{7}$ In our study, the rates of resistance to antibiotics used as initial empiric therapy (meropenem-vancomycin) for clinical decompensation were not high.

The systematic change of central venous lines is a controversial recommendation, although

TABLE 3. Bivariate analysis of risk factors

\begin{tabular}{|c|c|c|c|c|c|c|}
\hline & & Cases & Controls & Total & $p$ value & OR $(95 \% \mathrm{CI})$ \\
\hline \multirow[t]{2}{*}{ Age } & $\leq 12$ months & 6 & 5 & 11 & \multirow{2}{*}{0.11} & \multirow{2}{*}{$2.76(0.77-9.98)$} \\
\hline & $>12$ months & 23 & 53 & 76 & & \\
\hline \multirow{2}{*}{$\begin{array}{l}\text { Admission to the } \\
\text { operating room }\end{array}$} & Yes & 15 & 36 & 51 & \multirow{2}{*}{0.36} & \multirow{2}{*}{$0.65(0.27-1.61)$} \\
\hline & No & 14 & 22 & 36 & & \\
\hline \multirow[t]{2}{*}{ Urinary catheter } & Yes & 26 & 45 & 71 & \multirow{2}{*}{0.17} & \multirow{2}{*}{$2.5(0.65-9.61)$} \\
\hline & No & 3 & 13 & 16 & & \\
\hline \multirow[t]{2}{*}{ Length of stay (days) } & $>14$ days & 19 & 35 & 54 & \multirow[t]{2}{*}{0.64} & \multirow{2}{*}{$1.25(0.49-3.16)$} \\
\hline & $\leq 14$ days & 10 & 23 & 33 & & \\
\hline \multirow[t]{2}{*}{ MV } & $>14$ days & 14 & 21 & 35 & \multirow[t]{2}{*}{0.27} & \multirow[t]{2}{*}{$1.64(0.66-4.06)$} \\
\hline & $\leq 14$ days & 15 & 37 & 52 & & \\
\hline \multirow[t]{2}{*}{ CVL } & $>7$ days & 16 & 16 & 32 & \multirow{2}{*}{0.017} & \multirow{2}{*}{$3.18(1.20-8.38)$} \\
\hline & $\leq 7$ days & 11 & 35 & 46 & & \\
\hline \multirow[t]{2}{*}{ Burn surface area } & $>30 \%$ & 24 & 46 & 70 & \multirow{2}{*}{0.7} & \multirow{2}{*}{$1.25(0.39-3.97)$} \\
\hline & $\leq 30 \%$ & 5 & 12 & 17 & & \\
\hline
\end{tabular}

MV: mechanical ventilation, CVL: central venous line, OR: odds ratio, CI: confidence interval.

TABLE 4. Microbiological isolation by microorganism and site

\begin{tabular}{lcccc}
\hline Microorganism & $\begin{array}{c}\text { Blood culture } \\
(\mathbf{n}=\mathbf{2 9})\end{array}$ & $\begin{array}{c}\text { Skin culture } \\
(\mathbf{n}=\mathbf{1 3})\end{array}$ & $\begin{array}{c}\text { Catheter tip } \\
(\mathbf{n}=\mathbf{1 2})\end{array}$ & $\begin{array}{c}\text { Urine culture } \\
(\mathbf{n}=\mathbf{5})\end{array}$ \\
\hline Pseudomonas & 7 & 4 & 3 & 2 \\
Acinetobacter & 5 & - & 3 & 1 \\
Coagulase negative Staphylococcus & 4 & 4 & 2 & - \\
S. aureus & 3 & 3 & - & - \\
Enterococcus & 2 & - & 1 & 1 \\
Klebsiella & 2 & - & - & - \\
Serratia & 2 & - & - & - \\
Stenotrophomonas & 2 & 1 & - & - \\
Providencia & 1 & - & 1 & 1 \\
Candida & 1 & 1 & 1 & \\
\hline
\end{tabular}


placement for a prolonged time has been identified as a reversible risk factor. ${ }^{10,12,19}$ In our hospital, the recommendation is to place a new central venous line every 7 days. Fochtmann-Frana et al. corroborated catheter tip colonization of the central venous line in 200 out of 472 patients (42\%) after a mean of 12 days. For this reason, we believe it is logical, timely, and wise to change the central venous line every week, ${ }^{12}$ so as to reduce the risk evidenced in our study (OR: 3.18; $95 \%$ CI: 1.208.38). No data have been published in recent years in relation to the cutoff point for the systematic preventive change of central venous lines.

In addition, $13.8 \%$ of patients with bacteremia died, compared to $3.4 \%$ in the control group. Although death is a multi-cause phenomenon, ${ }^{20,21}$ patients with a greater burned body surface area, associated infections, ${ }^{22}$ and a longer length of stay have a higher mortality rate. ${ }^{14}$ Evidently, the high number of bacteremia cases in burn patients is a major problem for specialized centers due to its high morbidity and mortality, higher costs, and longer length of stay. Health care teams face major challenges in the future to reduce morbidity and mortality: knowing the local epidemiology, establishing an initial empiric antibiotic therapy protocol and bundles of measures for the placement and maintenance of central venous lines. ${ }^{23-25}$

It is worth noting that the main limitation of this study was the low prevalence of bacteremia events in the study period, which did not allow us to establish statistically significant associations. A prospective study design, with a larger sample size, where other factors and outcome measures affecting bacteremia can be assessed will allow to obtain statistically significant information and extrapolate data to the susceptible population.

\section{CONCLUSION}

In our study, the presence of a central venous line for more than 7 days showed a statistically significant association with bacteremia development; it was not possible to establish an association with other potential risk factors described in the bibliography. Pseudomonas, Acinetobacter, and coagulase-negative Staphylococcus were the most commonly identified microorganisms.

\section{Acknowledgments}

We would like to thank Verónica Álvarez, B.S., for her help and Alberto Belocchio, M.D., for his indispensable contribution.

\section{REFERENCES}

1. Cuenca-Pardo J, Álvarez-Díaz CJ, Comprés-Pichardo TA. Related factors in burn children. Epidemiological study of the Burn Unit at the "Magdalena de las Salinas" Traumatology Hospital. J Burn Care Res. 2008;29(3):468-74.

2. Rosanova MT, Stamboulian D, Lede R. Infecciones en los niños quemados: análisis epidemiológico y de los factores de riesgo. Arch Argent Pediatr. 2013; 111(4):303-8.

3. Rosanova MT, Mudryck G, Villasboas M, Basilico H, et al. Complicaciones infecciosas en pacientes quemados pediátricos. Rev Med Infant. 2009; 16(4):394-9.

4. Sheridan R. Sepsis in pediatric burn patients. Pediatr Crit Care Med. 2005; 6(3 Suppl):S112-9.

5. Ortiz Gil M, Mora Domínguez J, Aguilera Alfonso A. Colonización bacteriana y susceptibilidad antibacteriana de Pseudomonas aeruginosa aisladas de pacientes quemados infectados del Hospital Regional de Alta Especialidad de Veracruz. Enf Infec Microbiol. 2009; 29(1):11-9.

6. Chávez-Velarde T, Lona-Reyes J, Riebeling-Dueñas A, Orozco-Alatorre L. Incidencia y factores de riesgo para bacteriemia en pacientes pediátricos con quemaduras en un Centro de Atención Especializado en México. Rev Chil Infectol. 2017; 34(3):221-6.

7. Devrim I, Kara A, Düzgöl M, Karkiner A, et al. Burnassociated bloodstream infections in pediatric burn patients: Time distribution of etiologic agents. Burns. 2017;43(1):1448.

8. Rastegar Lari AR, Alaghehbandan R, Akhlaghi L. Burn wound infections and antimicrobial resistance in Tehran, Iran: an increasing problem. Ann Burns Fire Disasters. 2005; 18(2):68-73.

9. Rodgers L, Mortensen J, Fisher MC, Lo A, et al. Predictors of infectious complications after burn injuries in children. Pediatr Infect Dis J. 2000; 19(10):990-5.

10. Greenhalgh DG, Saffle JR, Holmes JH 4th, Gamelli RL, et al. American Burn Association Consensus Conference to Define Sepsis and Infection in Burns. J Burn Care Res. 2007; 28(6):776-90.

11. Tridente A. Sepsis 3 and the burns patient: do we need Sepsis 3.1? Scars Burns Heal. 2018; 4:2059513118790658.

12. Fochtmann-Frana A, Freystätter C, Vorstandlechner V, Barth A, et al. Incidence of risk factors for bloodstream infections in patients with major burns receiving intensive care: A retrospective single-center cohort study. Burns. 2018; 44(4):784-92.

13. Sabatier C, Peredo R, Vallés J. Bacteriemia en el paciente crítico. Rev Med Intensiva. 2009; 33(7):336-45.

14. Ekrami A, Kalantar E. Bacterial infections in burn patients at a burn hospital in Iran. Indian J Med Res. 2007; 126(6): 541-4.

15. Ramirez-Blanco CE, Ramirez-Rivero CE, Díaz-Martínez LA, Sosa-Ávila LM. Infection in burn patients in a referral center in Colombia. Burns. 2017; 43(3):642-53.

16. Hogan B, Wolf SE, Hospenthal DR, D'Avignon LC, et al. Correlation of American Burn Association sepsis criteria with the presence of bacteremia in burned patients admitted to the intensive care unit. J Burn Care Res. 2012;33(3):371-8.

17. Branski L, Al-Mousawi A, Rivero H, Jeschke MG, et al. Emerging Infections in Burns. Surg Infect (Larchmt). 2009; 10(5):389-97.

18. Núñez López O, Cambiaso-Daniel J, Branski LK, Norbury $\mathrm{WB}$, et al. Predicting and managing sepsis in burn patients: current perspectives. Ther Clin Risk Manag. 2017; 13:110717.

19. Franceschi D, Gerding R, Phillips G, Fratianne R. Risk factors associated with intravascular catheters infections in burned patients: a prospective, randomized study. J Trauma. 1989; 29(6):811-6. 
20. Vostrugina K, GudavièienëD, Vitkauskienë A. Bacteremias in patients with severe burn trauma. Medicina (Kaunas). 2006; 42(7):576-9.

21. Balmelli B, Sandoval J, Canata G. Infecciones en niños quemados internados en el Centro Nacional de Quemados y Cirugías Reconstructivas (CENQUER)Paraguay de Enero 2017 a Enero 2018. Rev Salud Pública Parag. 2018; 8(2):45-51.

22. Bang RL, Gang RK, Sanyal SC, Mokaddas E, et al. Burn septicaemia: an analysis of 79 patients. Burns. 1998; 24(4):354-61.
23. Devrim I, Oruç Y, Demirag B, Kara A, et al. Central line bundle for prevention of central line-associated bloodstream infection for totally implantable venous access devices (ports) in pediatric cancer patients. J Vasc Access. 2018; 19(4):358-65.

24. ISBIPracticeGuidelinesCommittee;SteeringSubcommittee; Advisory Subcommittee. ISBI practice guidelines for burn care. Burns. 2016; 42(5):953-1021.

25. Padilla Fortunatti CF. Impact of two bundles on central catheter-related bloodstream infection in critically ill patients. Rev Lat Am Enfermagem. 2017; 25:e2951. 